\title{
A particle swarm-based algorithm for optimization of multi-layered and graded dental ceramics
}

\author{
Ehsan Askari $^{\mathrm{a}, *}$, Paulo Flores ${ }^{\mathrm{b}}$, Filipe Silva ${ }^{\mathrm{b}}$ \\ a Department of Materials and Production, Aalborg University, Aalborg 9220, Denmark \\ b CMEMS, University of Minho, Campus de Azurém, 4800-058 Guimarães, Portugal
}

\section{A R T I C L E I N F O}

\section{Keywords:}

Dental restoration

Multi-layered and graded material

Porcelain

Ceramic

Particle swarm optimization

Thermal and bending stresses

\begin{abstract}
A B S T R A C T
The thermal residual stresses (TRSs) generated owing to the cooling down from the processing temperature in layered ceramic systems can lead to crack formation as well as influence the bending stress distribution and the strength of the structure. The purpose of this study is to minimize the thermal residual and bending stresses in dental ceramics to enhance their strength as well as to prevent the structure failure. Analytical parametric models are developed to evaluate thermal residual stresses in zirconia-porcelain multi-layered and graded discs and to simulate the piston-on-ring test. To identify optimal designs of zirconia-based dental restorations, a particle swarm optimizer is also developed. The thickness of each interlayer and compositional distribution are referred to as design variables. The effect of layers number constituting the interlayer between two based materials on the performance of graded prosthetic systems is also investigated. The developed methodology is validated against results available in literature and a finite element model constructed in the present study. Three different cases are considered to determine the optimal design of graded prosthesis based on minimizing (a) TRSs; (b) bending stresses; and (c) both TRS and bending stresses. It is demonstrated that each layer thickness and composition profile have important contributions into the resulting stress field and magnitude.
\end{abstract}

\section{Introduction}

Zirconia is material of interest to be used as the framework in dental restorations due to its superior mechanical properties and biocompatibility, enabling the prosthesis to withstand masticating loadings (Zarone et al., 2011; Denry and Kelly, 2008). As veneer, porcelain is also the common material of choice owing to its colour matching the remaining teeth and aesthetic (Fischer et al., 2008). In the production process of ceramic restoration, porcelain is fired onto the framework at high temperature. As constituting materials have different thermal expansion coefficients, the process of cooling temperature down to the room temperature leads to thermal residual stresses within the prosthesis (Baldassarri et al., 2011; Choi et al., 2011). On top of that, the mismatch of elastic characteristics between multi-material prostheses when subjected to occlusion loadings forms undesired stress fields along the corresponding interfaces (Choi et al., 2011; Swain, 2009). These all can lead to crack formation and propagation, veneer chipping and eventually catastrophic feature of the prosthesis (Choi et al., 2011; Swain, 2009; Isgrò et al., 2005; DeHoff and Anusavice, 2009; Tholey et al., 2011; Benetti et al., 2010; Baldassarri et al., 2012).

Making use of functionally graded materials (FGMs) can bypass drawbacks associated with the sharp transition from ceramic to porcelain. A typical FGM is an inhomogeneous composite made of different phases of constituent materials. By gradually varying the material composition involving constituent materials, the thermal and mechanical behavior of such materials vary smoothly and change continuously between different layers. This advantage eliminates interface problems of composite materials and the stress distribution becomes smooth. The influence of gradient variation of material properties in the FGMs on thermal residual stresses has been investigated by previous research studies analytically and numerically (Ravichandran, 1995; Becker et al., 2000; Koohbor et al., 2015; Birman and Byrd, 2007; Kesler et al., 1998; Cannillo et al., 2006). The readers interested in the origin and advancement of functionally graded materials are referred to very comprehensive review papers (Suresh and Mortensen, 1997; Mortensen and Suresh, 1995; Jha et al., 2013; Naebe and Shirvanimoghaddam, 2016). An interlayer with a gradation of properties between two base materials, the framework and the interlay, has therefore been used for dental restorations in order to reduce the mismatches in thermal and mechanical properties (Zhang and Kim, 2009, 2010; Y. Zhang et al., 2012; Chai et al., 2014; Z. Zhang et al., 2012). This solution has resulted in excellent load-bearing capacity, improved damage resistance and bond

\footnotetext{
* Corresponding author.

E-mail address: ehsanaskary@gmail.com (E. Askari).
} 
strength resistance, as a consequent of a reduction in resulting stresses associated with graded prostheses (Zhang and Kim, 2009; Y. Zhang et al., 2012; Henriques et al., 2012a, 2012b; Hsueha et al., 2008; Tsukada et al., 2014; Fabris et al., 2016). Moreover, design parameters of functionally graded restorations can significantly influence the resulting stress distribution and magnitude (Paul et al., 2016; Chen and Tong, 2005; Stump et al., 2007; Mohammadiha and Beheshti, 2014; Fereidoon et al., 2012). It is, therefore, of paramount importance to develop an optimization algorithm to optimize the thickness of each layer and the composition profile.

In addition to thermal residual stresses, the flexural strength of ceramic restorations plays very important role in the performance and longevity of dental implants. The biaxial flexure tests are commonly employed to evaluate flexural strengths of dental materials. The associated stresses can also mimic multiaxial loading nature existing due to occlusion forces on restoration (Thompson, 2004; Hsueh et al., 2006a). In biaxial tests, the sample is supported on either three balls or a ring near its periphery and a load is applied on its upper surface through a piston placed at the centre of the specimen (Thompson, 2004). Due to loading and boundary conditions, a multiaxial stress state is generated near the specimen's centre, eliminating undesired edge failures taking place in uniaxial tests (Hsueh et al., 2006b).

The particle swarm optimization (PSO) is generally a populationbased optimization algorithm based on the hypothesis that social sharing of information among conspecifics offers an evolutionary advantage (Kennedy and Eberhart, 1995). The population of PSO is called a swarm and each individual in the population of PSO is called a particle, which adjusts its position in the search space regarding its own social experience and the social experience of the community ( $\mathrm{He}$ et al., 2004a). The PSO algorithm involves in adjusting very few parameters, which makes it easy to implement. The particle swarm optimization has been applied to a broad range of engineering problems in the literature and has shown a faster convergence rate than other evolutionary algorithms (He et al., 2004b; Fourie and Groenwold, 2002; Liu et al., 2016; Mavrovouniotis et al., 2017; Loja, 2014; Kathiravan and Ganguli, 2007; Mashhadban et al., 2016; Li et al., 2007; Chang et al., 2010; Jun et al., 2016).

The present study, therefore, aims to develop a particle swarm optimizer to identify optimal designs of multi-layered and graded dental restorations. The methodology consists of two main parts: (i) simulating thermal residual stresses and the piston-on-ring test analytically; (ii) developing a particle swarm-based algorithm to optimize the design of zirconia-based dental ceramics aiming to minimize resultant stresses. The contribution of the current research work is to develop a procedure to optimize the design of ceramic dental restoration, which can be generalized in order for the optimization of any combinations of multilayered and graded dental implants. The thickness of each layer and compositional distribution exponent are referred to as design variables. The effect of layer numbers constituting the interlayer between two based materials on graded prosthetic systems is also investigated. A finite element model is constructed to verify the developed methodology, although acquired results are compared to those available in literature. Three different optimization cases are considered to determine the optimal design of graded prosthesis by minimizing (a) TRSs; (b) bending stresses; and (c) both TRS and bending stresses. It is demonstrated that each layer thickness and composition profile have important influences on the stress field and magnitude.

\section{Mathematical modelling}

For the graded material, a stepwise gradation between the two base materials is considered such that each disc consists of a number of layers each of which is made of a specific homogenous material. The top and bottom layers are monolithic porcelain and zirconia, respectively. The intermediate layers are composed from a mixture of porcelain and zirconia. In order to calculate mechanical properties of each

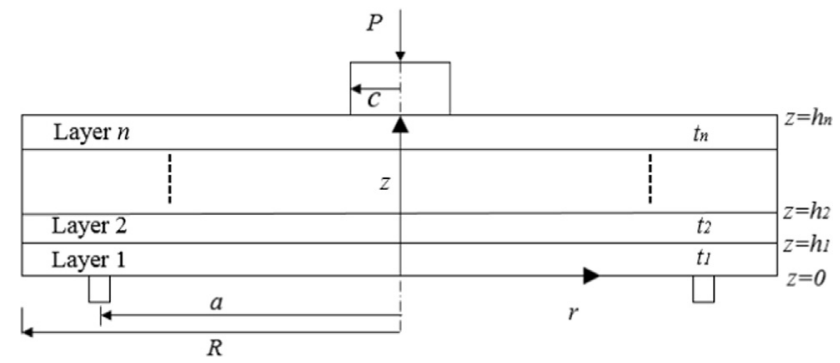

Fig. 1. A schematic representation of the piston-on-ring test with a multi-layered circular disc as the sample.

intermediate layer, a continuous change in the volume fraction of porcelain through the thickness is considered. This change is taken into account by a power law function, as follows:

$\mathrm{V}_{\mathrm{p}}=\left(\frac{\mathrm{z}}{\mathrm{t}}\right)^{\mathrm{p}}$

where $V_{p}$ stands for the volume fraction of porcelain, $z$ is the distance from the bottom, Fig. 1 , and $t$ is the overall thickness. For different values of $p$, the concentration of zirconia and porcelain through the thickness varies. The mechanical properties of intermediate layers, i.e. Young's modulus, Poisson's ratio and thermal expansion coefficient, are determined using the Voigt's rule of mixtures given by (Moshkelgosha et al., 2017; Shafiee et al., 2014)

$\mathrm{P}_{\mathrm{i}}=\mathrm{P}_{\mathrm{z}} \mathrm{V}_{\mathrm{z}}+\mathrm{P}_{\mathrm{p}} \mathrm{V}_{\mathrm{p}}$

where $P_{i}$ is the property of the $i$ th layer, $P_{z}$ and $P_{p}$ are the properties of the zirconia and porcelain, respectively. $V_{z}$ and $V_{p}$ are the volume fractions of zirconia and porcelain composition, respectively. The mechanical properties of the base materials are listed in Table 1.

\subsection{Thermal residual stress}

Considering a disc consisting of several layers, the gradient change of material through the thickness is taken into account. It is assumed that materials remain within the elastic region as well as layers remain bonded over simulation, consequently no slippage between layers takes place. A uniform temperature is considered throughout the plate and no stress relaxation is taken into account during the cooling-down process. The thermal residual stresses through the thickness of the disc can be calculated using laminate theory (Shaw, 1998; Bouchafa et al., 2010):

$\sigma=\widetilde{\mathbf{Q}} \varepsilon=\widetilde{\mathbf{Q}}\left(\varepsilon^{0}+z \kappa-\alpha \Delta T\right)$

$\widetilde{\mathbf{Q}}$ stands for the matrix of the material stiffness and $\varepsilon$ is thermal residual strain vector at location $z$. while $\varepsilon^{0}$ is the mid-plane strain, $\kappa$ the vector of the plate curvature, $\alpha$ the coefficient vector of thermal expansion of material as a function of location $z$, and finally $\Delta T$ is the steady-state temperature variation. A polar coordinate system regarding the disc geometry is also considered as $(r, \theta, z)$. Considering the plate to be isotropic at each layer, non-zero stress components are $\sigma_{r}$ and $\sigma_{\theta}$. To compute residual stresses in Eq. (3), the mid-plane strains and curvatures of the circular plate can be determined from

Table 1

Material properties of Zirconia and porcelain $\left(25^{\circ} \mathrm{C}\right)$.

\begin{tabular}{lll}
\hline & Zirconia & Porcelain \\
\hline $\mathrm{E}(\mathrm{GPa})$ & $210\left(200^{\mathrm{a}}\right)$ & 70 \\
$v$ & 0.3 & 0.26 \\
$\alpha\left(\mathrm{K}^{-1}\right)$ & $10.17 \mathrm{e}-6\left(10.86^{\mathrm{a}}\right)$ & $9.05 \mathrm{e}-6\left(9.40^{\mathrm{a}}\right)$
\end{tabular}

a The average value obtained within the range of temperature variation during the cooling down process (Becker et al., 2000). 
$\left[\begin{array}{l}\mathbf{N}^{T} \\ \mathbf{M}^{T}\end{array}\right]=\left[\begin{array}{ll}\mathbf{A} & \mathbf{B} \\ \mathbf{B} & \mathbf{D}\end{array}\right]\left[\begin{array}{l}\varepsilon^{0} \\ \boldsymbol{\kappa}\end{array}\right]$

where $\mathbf{N}^{T}$ and $\mathbf{M}^{T}$ are the normal force and moment resulting from the internal stress distribution that can be defined as follows:

$\mathbf{N}^{T}=\int_{-\frac{h}{2}}^{\frac{h}{2}} \sigma^{T} d z, \quad \quad \mathbf{M}^{T}=\int_{-\frac{h}{2}}^{\frac{h}{2}} \sigma^{T} z d z$

in which $\sigma^{T}$ is given by $\widetilde{\mathbf{Q}} \alpha \Delta T$. Matrix components in Eq. (4) are also the stiffness matrices of the plate, which are given by

$\mathbf{A}=\int_{-\frac{h}{2}}^{\frac{h}{2}} \widetilde{\mathbf{Q}} d z ; \quad \mathbf{B}=\int_{-\frac{h}{2}}^{\frac{h}{2}} \widetilde{\mathbf{Q}} z d z ; \quad \mathbf{D}=\int_{-\frac{h}{2}}^{\frac{h}{2}} \widetilde{\mathbf{Q}} z^{2} d z$

\subsection{The piston-on-ring test}

The piston-on-ring test consists of a disc supported by a rigid ring at the inferior face. Through a piston, a perpendicular force $P$ is applied on the top of the disc, as shown in Fig. 1. It results in tensile stresses within the zirconia layer at the bottom of the disc. In addition, a biaxial moment throughout the disc thickness is generated due to the applied force. The disc is of a radius $R$, while the supporting ring has a radius $a$, and the loading piston placed at the centre of the disc has a radius $c$. In the present study, the stepwise graded discs are divided into several bonded layers each of which has a different composition and, therefore, different properties. The disc consists of $n$ layers of individual thickness $t_{i}$, where $i$ is the layer number. Layer 1 (zirconia) is located at the bottom of the disc, and layer $n$ (porcelain) is at the top. The interface between the $i$ th and $(i+1)$ th layers is located at $z=h_{i}$. The bottom of the disc was located at $z=h_{0}=0$ and the top at $z=h_{n}$.

\subsubsection{An analytical model to determine bending stresses}

The standard "ISO 6872" allows to calculate the biaxial flexure strength only for mono-layered discs. However, an analytical solution was proposed by Hsueh et al. (2006a, 2006b); Huang and Hsueh (2011) to calculate the stress distribution in multilayered discs. Hsueh et al. formula was derived based on the ISO 6872 formulae and presented good accuracy compared with numerically simulated models for trilayered systems (Hsueh et al., 2006a). The stress due to bending moment in a multilayer disc is given by:

$\sigma_{i}=\frac{E_{i}\left(z-z^{*}\right) M}{\left(1-v_{i}\right)\left(1+v_{\text {ave }}\right) D^{*}}$

where $E_{i}$ and $v_{i}$ are Young's modulus and Poisson's ratio of the ith layer, respectively. $M$ is the biaxial bending moment per unit length, $z^{*}$ the position of the neutral plane, $D^{*}$ the flexural rigidity, and finally $v_{\text {ave }}$ is average Poisson's ratio. $E_{i}$ and $v_{i}$ are calculated by Eq. (2), and other variables are computed as follows:

$z^{*}=\frac{\sum_{i=1}^{n}\left(\frac{E_{i} t_{i}}{1-v_{i}^{2}}\right)\left(h_{i-1}+\frac{t_{i}}{2}\right)}{\sum_{i=1}^{n} \frac{E_{i} t_{i}}{1-v_{i}^{2}}}$

$D^{*}=\sum_{i=1}^{n} \frac{E_{i} t_{i}}{1-v_{i}^{2}}\left[h_{i-1}^{2}+h_{i-1} t+\frac{t_{i}^{2}}{2}-\left(h_{i-1}+\frac{t_{i}}{2}\right) z^{*}\right]$

$v_{\text {ave }}=\frac{1}{h_{n}} \sum_{i=1}^{n} v_{i} t_{i}$

$M=\frac{-P}{8 \pi}\left\{\left(1+v_{\text {ave }}\right)\left(1+2 \ln \frac{a}{c}\right)+\left(1-v_{\text {ave }}\right)\left[\left(1-\frac{c^{2}}{2 a^{2}}\right) \frac{a^{2}}{R^{2}}\right]\right\}$

$R, a$ and $c$ are geometrical variables, as are indicated in Fig. 1. For $n=$ 1 (only one layer), Hsueh et al. formula can be reduced to the ISO 6872 mono-layered disc formula. Therefore, the formula can be used to evaluate the stress moment for both mono-layered and multi-layered discs.
Table 2

Values of the variable limits.

\begin{tabular}{llll}
\hline \multicolumn{2}{l}{ Limits of the thickness of $i$ th layer $(\mathrm{mm})$} & \multicolumn{2}{l}{ Limits of the compositional distribution } \\
\hline$t_{i}^{l}$ & $t_{i}^{u}$ & $p^{l}$ & $p^{u}$ \\
0.05 & 1.60 & 0.01 & 10 \\
\hline
\end{tabular}

\subsection{Optimization problem}

The goal of this study is to obtain the optimal thickness and compositional distribution of functionally graded dental restorations, minimizing TRSs and bending stresses (BSs) within the FG discs. Design variables are the thicknesses of individual layers and compositional distribution. Mathematically, the above optimization problems can be formulated as follows:

$$
\left\{\begin{array}{c}
\text { Minimize } f(\mathbf{X})=\operatorname{Max}(T R S+B S) \\
\mathbf{X}=\left(t_{1}, t_{2}, \ldots, t_{n}, p\right) \\
t_{i}^{l} \leq t_{i} \leq t_{i}^{u}, 1 \leq i \leq n \\
p^{l} \leq p \leq p^{u}
\end{array}\right.
$$

where $f(\mathbf{X})=\operatorname{Max}(T R S+B S)$ is the objective function. The vector of variables $\mathbf{X}$ stands for the set of design variables, while $t_{i}$ is the thickness of $i$ th layer and $p$ is the power exponent controlling the shape of composition gradient. The values $t_{i}^{l}$ and $t_{i}^{u}$ are the lower and upper bounds of the thickness of $i$ th layer, while $p^{l}$ and $p^{u}$ are the lower and upper bounds of the power $(p)$, respectively, as listed in Table 2 .

\subsubsection{Particle swarm optimization algorithm}

The particle swarm optimization is based on the hypothesis that social sharing of information among conspecifics offers an evolutionary advantage (Kennedy and Eberhart, 1995). The PSO is a populationbased optimization algorithm. The population of PSO is called a swarm and each individual in the population of PSO is called a particle. The ith particle at an iteration $k$ has the following two attributes:

(1) A current position in an $N$-dimensional search space $\mathbf{X}_{i}^{k}=\left(x_{1}^{k}, \ldots, x_{n}^{k}, \ldots x_{N}^{k}\right)$, in which $x_{n}^{k} \in\left[l_{n}, u_{n}\right], 1 \leq n \leq N, l_{n}$ and $u_{n}$ are lower and upper bounds for the $n$th dimension, respectively.

(2) A current velocity $\mathbf{V}_{i}^{k}, \mathbf{V}_{i}^{k}=\left(v_{1}^{k}, \ldots, v_{n}^{k}, \ldots, v_{N}^{k}\right)$, which is bounded by a maximum velocity $\mathbf{v}_{\max }^{k}=\left(v_{\max , 1}^{k}, \ldots, v_{\max , n}^{k}, \ldots, v_{\max , N}^{k}\right)$ and a minimum velocity $\mathbf{v}_{\min }^{k}=\left(v_{\text {min }, 1}^{k}, \ldots, v_{\min , n}^{k}, \ldots, v_{\min , N}^{k}\right)$.

In each iteration of the PSO, the swarm is updated by the following governing equations (Kennedy and Eberhart, 1995):

$\mathbf{V}_{i}^{k+1}=\omega \mathbf{V}_{i}^{k}+c_{1} r_{1}\left(\mathbf{P}_{b}^{k}-\mathbf{X}_{i}^{k}\right)+c_{2} r_{2}\left(\mathbf{P}_{g}^{k}-\mathbf{X}_{i}^{k}\right)$

$\mathbf{X}_{i}^{k+1}=\mathbf{X}_{i}^{k}+\mathbf{V}_{i}^{k+1}$

where $\mathbf{P}_{b}$ is the best previous position of the $i$ th particle, also known as pbest, and $\mathbf{P}_{g}$ is the best global position (gbest) among all the particles in the swarm. $\mathbf{P}_{b}$ and $\mathbf{P}_{g}$ are given by the following equations, respectively:

$\mathbf{P}_{b}=\left\{\begin{array}{l}\mathbf{P}_{b}: f\left(\mathbf{X}_{i}\right) \geq f\left(\mathbf{P}_{b}\right) \\ \mathbf{X}_{i}: f\left(\mathbf{X}_{i}\right)<f\left(\mathbf{P}_{b}\right)\end{array}\right.$

$\mathbf{P}_{g} \in\left\{\mathbf{P}_{0}, \mathbf{P}_{1}, \ldots, \mathbf{P}_{m}\right\} \mid f\left(\mathbf{P}_{g}\right)=\min \left(f\left(\mathbf{P}_{0}\right), f\left(\mathbf{P}_{1}\right), \ldots, f\left(\mathbf{P}_{m}\right)\right)$

in which $f$ is the objective function, $m<M$ where $M$ is the total number of particles, $r_{1}$ and $r_{2}$ are elements from two uniform random sequences in the range of $(0,1)$, and $\omega$ is an inertia weight (Shi and Eberhart, 1997), which is typically initialized in the range of [0,1]. A larger inertia weight facilitates global exploration, while a smaller inertia weight tends to facilitate local exploration to fine-tune the current search area (Eberhart and Shi, 2001). The variable $c_{1}$ and $c_{2}$ are 
acceleration constants, which control how far a particle will move in a single iteration. The acceleration constants $c_{1}$ and $c_{2}$ indicate the stochastic acceleration terms which pull each particle towards the best position attained by the particle or the best position attained by the swarm. Low values of $c_{1}$ and $c_{2}$ allow the particles to wander far away from the optimum regions before being tugged back, while the high values pull the particles toward the optimum or make the particles to pass through the optimum abruptly. In the present study, $c_{1}=2$ and $c_{2}=2$ are chosen.

The role of the inertia weight $\omega$ is considered important for the convergence behavior of the PSO algorithm. The inertia weight is employed to control the impact of the previous history of velocities on the current velocity. Thus, the parameter $\omega$ regulates the trade-off between the global (wide ranging) and the local (nearby) exploration abilities of the swarm. A proper value for the inertia weight $\omega$ provides balance between the global and local exploration ability of the swarm, and thus results in better solutions. Numerical tests imply that it is preferable to initially set the inertia to a large value, to promote global exploration of the search space, and gradually decrease it to obtain refined solutions (Kennedy and Eberhart, 1995). Thus, a dynamic variation of inertia weight proposed in Fourie and Groenwold (2002) is used in this paper. The inertia weight $\omega$ is decreased dynamically based on a fraction multiplier $k_{\omega}$ as is shown below

$\omega_{k+1}=k_{\omega} \omega_{k}$

\subsection{Finite element method}

Finite element method is employed to determine thermal residual stresses distributed within the disc due to cooling process and use the associated stress state as initial condition for the biaxial test modelling. ANSYS Workbench (version 16.2) as a commercial software is used to carry out the simulation. As the problem is axisymmetric, a 2-D FE axisymmetric model is constructed. At the beginning of the simulation, the disc is assumed to be at the processing temperature, cooling down to the ambient temperature. In the simulation, the ring is fully constrained, supporting the disc, and a constant force is applied at the superior surface of the piston to transfer a uniform force to the disc. The supporting ring was fixed and the piston can move just in the vertical axis, z. As a simplification, it is considered that layers remain bonded over the simulation. The structure is discretized into elements with very fine meshes to guarantee accuracy of results. The mesh refinement is applied to elements near to the contact area between the piston and disc to avoid singularities in the stress distribution. Moreover, finer meshes are used along the interfaces to enhance the accuracy of composition gradient in samples. It is worth mentioning that finite element analyses are just performed for optimal designs obtained by the PSO model.

\subsection{A brief discussion on fabrication of functionally-graded ceramics}

The optimization model developed in the present study provides an optimal functionally-graded ceramic dental restoration, minimizing tensile stresses through the structure. What the model gives a user as outputs are (i) an optimal compositional exponent from which porcelain/zirconia volume fraction can be evaluated for each layer; (ii) an optimal number of layers constituting the structure; and (iii) an optimal thickness of each layer. Two main steps of FGCs fabrication are gradation and consolidation (Besisa and Ewais, 2016; Naebe and Shirvanimoghaddam, 2016). The former is the building of the spatially inhomogeneous graded structure and the consolidation is to transfer this graded structure into the bulk material. The gradation process is commonly categorized as constitutive, homogenizing and segregating processes (Besisa and Ewais, 2016). The gradation process of a FGC dental restoration is made by mixing different volume fractions of the porcelain and zirconia components. Therefore, a mixture of powder materials for each layer of the corresponding optimal design is prepared. Stacking layer by layer is the easiest method for obtaining a compact (Zhang et al., 2010; Chai et al., 2014; Tsukada et al., 2014). The powder for the first layer is inserted into the die and pressed by punch lightly. Sequentially, the next layer is stacked until the last layer (Tsukada et al., 2014; Villefort et al., 2017). Multiple techniques have been introduced for powder preparation, such as chemical reaction, electrolytic deposition, grinding and comminution, which offer a controllable size range of the final grain population. Moreover, some challenges involved in stacking process include warping, crack initiation and propagation and frustum formation. Lamination can take place in final products owing to unpredictable distribution of particles (Besisa and Ewais, 2016; Naebe and Shirvanimoghaddam, 2016). In the subsequent processes, the consolidation can be performed by a variety of production methods, such as (1) powder sintering as the main mechanism of powder consolidation in a solid component; (2) hot pressing under temperature and pressure, simultaneously, with induction heating; (3) cold pressing by a cold pressing followed by sintering; (4) spark plasma sintering by charging the intervals between powder particles with electrical energy (Besisa and Ewais, 2016; Naebe and Shirvanimoghaddam, 2016; Zhang et al., 2010; Chai et al., 2014; Tsukada et al., 2014; Villefort et al., 2017). Most of these methods are based on variations of conventional processing methods being already well-stablished. It is interesting to note that the model developed in the present study and available fabrication processes can also be employed to optimize designs of functionallygraded coatings to improve the tribology performance of ceramic-onceramic hip implants to decrease wear and to eliminate hip squeaking (Askari et al., 2016, 2015).

\subsection{Example analysis}

As demonstrative examples of application, the numerical method is implemented to a $3 \mathrm{~mm}$ layered disc with a radius of $4 \mathrm{~mm}$, modeled with three main layers, which mimics the three components of a dental restoration: the framework, the veneer and the interlayer with intermediate properties. The disc is subjected to a cooling simulating manufacturing process of dental restorations, that is, the disc is cooled from $550{ }^{\circ} \mathrm{C}$ to $20^{\circ} \mathrm{C}$. The thickness of specimen is assumed to be $3 \mathrm{~mm}$ of which the zirconia layer, bottom layer, and the top layer, porcelain, are $0.7 \mathrm{~mm}$ and the whole interlayer has $1.6 \mathrm{~mm}$ thickness.

The equations and optimization problem introduced in the Section 2 are resolved using the above PSO algorithm. For all optimization problems, a population of 70 particles is used, while the maximum number of iterations is limited to 500 iterations. The stopping criterion can be defined based on the number of iterations without updating in the best values of the swarm or the number of iteration the algorithm execute. Although the latter is not a real physical stopping criterion, it is quite easy in programming implementation and hence widely used in the PSO algorithms.

Three different cases are considered optimizing the design of dental restorations by minimizing ( $a$ ) TRSs; (b) bending stresses due to the piston-on-ring tests; and $(c)$ both TRSs and bending stresses. Moreover, different numbers of layers constituting the interlayer are studied. The numerical analyses focus on design variables, thicknesses of the layers of the interlayer and the composition profile. In addition, the convergence study of the PSO algorithm and the validation of the methods developed within the present study against available literature and a finite element model are presented. Moreover, a user-friendly application is written enabling to optimize graded restorations with different sizes, material properties, manufacturing process, layers number, etc., as is depicted in Fig. 2 to just represent how the application works. It is worth stating that TB as the processor is an abbreviation of "TRS" and "Bending stress". 


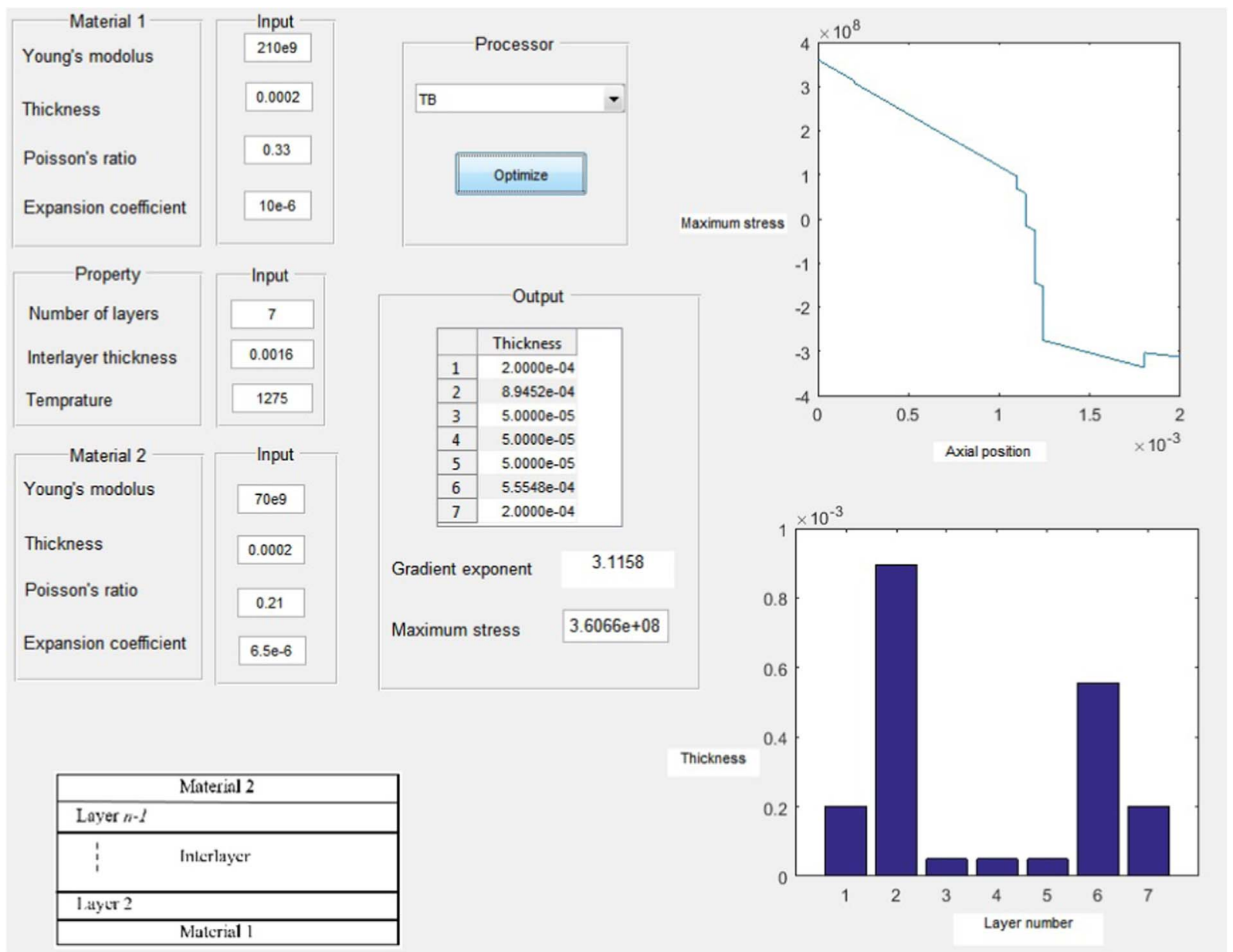

Fig. 2. A user-friendly application, developed within the present study, to do optimization. An example is also represented to clarify the app capability.

\section{Results and discussion}

\subsection{Minimizing the TRSs by controlling the design variables}

For the graded material, a stepwise gradation between the two base materials is considered such that each the interlayer is consisted of a number of layers each of which is made of a specific homogenous material regarding the Voigt's rule of mixtures. The maximum thermal residual stress for a sharp transition from the zirconia to porcelain layer is computed, which is $50.71 \mathrm{MPa}$. Moreover, the optimization procedure is employed targeting to minimize thermal residual stresses. Optimal designs of multi-layered disc with different layer numbers are listed in Table 3. As can be seen, the prosthesis design with 6 layers obtains the minimum stress among others, from which it can be concluded that the best design is not necessarily the one with too many
Table 4

Corresponding Young's Modulus of each layer presented in Table 3 for the disc subjected to thermal stresses.

\begin{tabular}{lllllllll}
\hline \multirow{2}{*}{ No. of layers } & \multicolumn{9}{l}{ Young's modulus (GPa) } \\
\cline { 2 - 9 }$n$ & $t_{2}$ & $t_{3}$ & $t_{4}$ & $t_{5}$ & $t_{6}$ & $t_{7}$ & $t_{8}$ & $t_{9}$ \\
\hline 3 & 148 & & & & & & & \\
4 & 183 & 134 & & & & & & \\
5 & 174 & 139 & 104 & & & & & \\
6 & 193 & 168 & 138 & 105 & & & & \\
7 & 203 & 187 & 166 & 138 & 106 & & & \\
8 & 196 & 179 & 159 & 138 & 116 & 94 & & \\
9 & 193 & 175 & 158 & 140 & 123 & 105 & 88 & \\
10 & 188 & 171 & 155 & 140 & 125 & 111 & 97 & 83 \\
& & & & & & & & \\
\end{tabular}

Table 3

Optimal outcomes of the design variables for the disc subjected to thermal stresses.

\begin{tabular}{|c|c|c|c|c|c|c|c|c|c|c|}
\hline \multirow{2}{*}{$\begin{array}{l}\text { No. of layers } \\
n\end{array}$} & \multicolumn{9}{|c|}{ Design variables } & \multirow{2}{*}{$\begin{array}{l}\text { Max stress } \\
\sigma_{M}(\mathrm{MPa})\end{array}$} \\
\hline & $t_{2}$ & $t_{3}$ & $t_{4}$ & $t_{5}$ & $t_{6}$ & $t_{7}$ & $t_{8}$ & $t_{9}$ & $p$ & \\
\hline 3 & 1.6 & & & & & & & & 1.17 & 29.58 \\
\hline 4 & 0.545 & 1.055 & & & & & & & 1.51 & 20.93 \\
\hline 5 & 0.756 & 0.773 & 0.071 & & & & & & 0.98 & 20.26 \\
\hline 6 & 0.093 & 0.765 & 0.693 & 0.050 & & & & & 1.31 & 20.12 \\
\hline 7 & 0.050 & 0.073 & 0.699 & 0.653 & 0.125 & & & & 1.66 & 20.66 \\
\hline 8 & 0.052 & 0.221 & 0.728 & 0.331 & 0.205 & 0.063 & & & 1.20 & 21.08 \\
\hline 9 & 0.062 & 0.365 & 0.386 & 0.341 & 0.321 & 0.056 & 0.069 & & 1.01 & 21.68 \\
\hline 10 & 0.131 & 0.356 & 0.397 & 0.308 & 0.237 & 0.057 & 0.051 & 0.062 & 0.85 & 21.68 \\
\hline
\end{tabular}




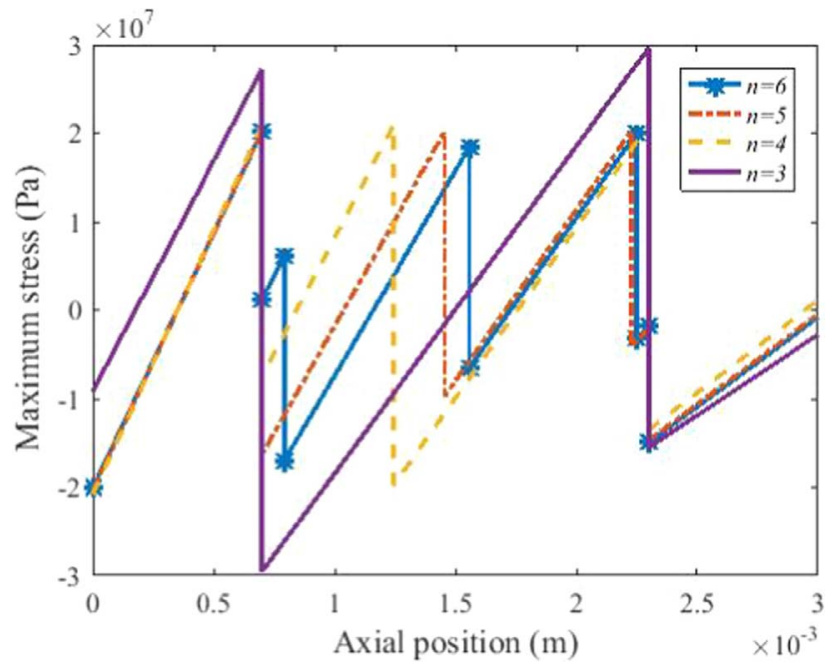

Fig. 3. The distribution of thermal residual stress along the central axis for four first optimal designs presented in Table 3. Maximum mismatch stresses of these optimal designs are: (1) $n=3,56.8 \mathrm{MPa}$; (2) $n=4,40.7 \mathrm{MPa}$; (3) $n=5$, $36.5 \mathrm{MPa}$; (4) $n=6$, 24.8 MPa.

inter-layers. An increase in resulting maximum stresses is observed as the number of layers exceeds six. It is worth noting that the maximum stress reported for the case with a sharp transition is 2.5 times greater than the design with 6 layers. Table 4 lists Young's modulus of intermediate layers associated with corresponding optimized designs. These information provide a useful database to facilitate the process of decision making to design a prosthesis which fulfils associated requirements in terms of application and manufacturing.

As discussed previously in the introduction, the mismatch of mechanical properties between multi-material prostheses can lead to undesired stress fields along interfaces. Fig. 3 indicates the distribution of TRS along the central axis of a number of optimal designs listed in Table 3 including the best design. Sharp stress transition along interfaces due to mismatch in mechanical properties are observable. These undesired stress variation can contribute to crack formation and propagation, etc. The minimum mismatch stress occurs in the case of the best design with six layers, which is $25 \mathrm{MPa}$, while it is 57 in the case of design with three layers. It can be concluded that the best design also fulfils the requirement for having less mismatch stress along interfaces.

The convergence rate of the optimization procedure is also studied and shown in Fig. 4. The thickness of an intermediate layer converges to a constant value just before 100 iteration, while the convergence study for all numerical analyses illustrates the convergence occurs in less than 200 iteration showing the PSO is a fast optimizer. A finite element model is also constructed and the maximum stress and stress distribution profiles corresponding the optimal design with six layers are obtained. The results acquired from the present model align with those from FEA.

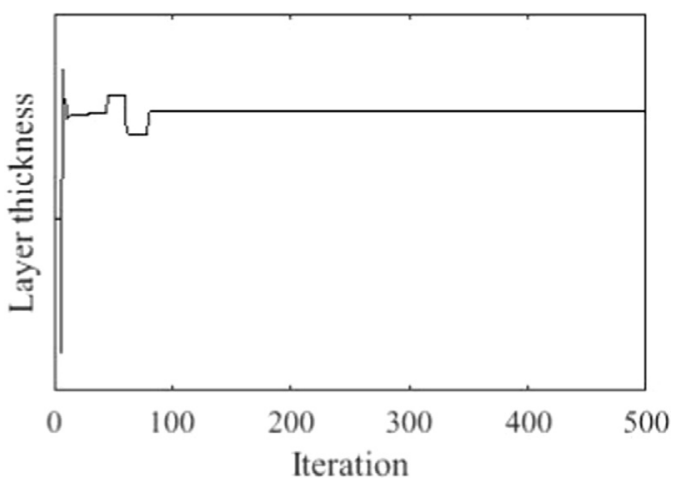

Fig. 4. Convergence rate of the optimization procedure.
Table 5

Comparison optimal results of the design variables with those obtained by $\mathrm{Xu}$ et al. (2012).

\begin{tabular}{|c|c|c|c|c|c|c|}
\hline \multirow{2}{*}{$\begin{array}{l}\text { Layer } \\
\text { number }\end{array}$} & \multicolumn{3}{|l|}{ Present study } & \multicolumn{3}{|l|}{ Xu et al. } \\
\hline & $\mathrm{p}=0.0739$ & $\mathrm{p}=0.5$ & $\mathrm{p}=1$ & $\mathrm{p}=0.0739$ & $\mathrm{p}=0.5$ & $\mathrm{p}=1$ \\
\hline$t_{1}$ & 0.0099 & 0.0099 & 0.0099 & 0.0106 & 0.0099 & 0.0100 \\
\hline$t_{2}$ & 0.0999 & 0.0099 & 0.0099 & 0.0995 & 0.0100 & 0.0100 \\
\hline$t_{3}$ & 0.0999 & 0.0099 & 0.0099 & 0.0997 & 0.0100 & 0.0100 \\
\hline$t_{4}$ & 0.0999 & 0.0099 & 0.0099 & 0.0999 & 0.0099 & 0.0100 \\
\hline$t_{5}$ & 0.1000 & 0.0099 & 0.0099 & 0.0999 & 0.0100 & 0.0100 \\
\hline$t_{6}$ & 0.0999 & 0.0099 & 0.0099 & 0.0999 & 0.0099 & 0.0100 \\
\hline$t_{7}$ & 0.0999 & 0.0099 & 0.0099 & 0.0999 & 0.0100 & 0.0100 \\
\hline$t_{8}$ & 0.0999 & 0.0099 & 0.0099 & 0.0998 & 0.0099 & 0.0100 \\
\hline$t_{9}$ & 0.0999 & 0.0099 & 0.0099 & 0.0999 & 0.0100 & 0.0100 \\
\hline$t_{10}$ & 0.1000 & 0.0099 & 0.0099 & 0.0999 & 0.0100 & 0.0100 \\
\hline$t_{11}$ & 0.0999 & 0.0099 & 0.0099 & 0.0999 & 0.0100 & 0.0100 \\
\hline$t_{12}$ & 0.0999 & 0.1000 & 0.0099 & 0.0999 & 0.0999 & 0.0099 \\
\hline$t_{13}$ & 0.0999 & 0.1000 & 0.0099 & 0.0999 & 0.0999 & 0.0100 \\
\hline$t_{14}$ & 0.0999 & 0.1000 & 0.0099 & 0.0999 & 0.0999 & 0.0100 \\
\hline$t_{15}$ & 0.0965 & 0.1000 & 0.0099 & 0.0872 & 0.0999 & 0.0100 \\
\hline$t_{16}$ & 0.0934 & 0.1000 & 0.1000 & 0.0872 & 0.0999 & 0.0999 \\
\hline$t_{17}$ & 0.0982 & 0.1000 & 0.1000 & 0.0988 & 0.0999 & 0.0999 \\
\hline$t_{18}$ & 0.0988 & 0.1000 & 0.1000 & 0.0993 & 0.0999 & 0.0999 \\
\hline$t_{19}$ & 0.0999 & 0.1000 & 0.1000 & 0.0999 & 0.0999 & 0.0999 \\
\hline$t_{20}$ & 0.0996 & 0.1000 & 0.1000 & 0.0996 & 0.0999 & 0.0999 \\
\hline
\end{tabular}

Results obtained from the developed method are also compared to the problem resolved by Xu et al. (2012), where a PSO algorithm was developed to minimize the TRSs in $\mathrm{C} / \mathrm{SiC}$ graded coating of $\mathrm{C} / \mathrm{C}$ composites. Furthermore, the comparison indicates a very good consistent between the outcomes, presented in Table 5. The maximum thermal residual stress acquired by the present study for the case with the compositional exponent of 0.0739 is $188 \mathrm{MPa}$, which shows $7.5 \%$ discrepancy with the original study by $\mathrm{Xu}$ et al.

\subsubsection{Minimizing thermal residual stresses within the veneer}

One major reason behind introduction of FGMs is to mitigate crack formation in the more brittle layers by lowering the overall internal stress levels developed during fabrication. Porcelain fused to zirconia (PFZ) restorations suffers from the susceptibility of porcelain to premature fracture (Chai et al., 2014; Choi et al., 2011; Sailer et al., 2009; Sax et al., 2011; Tan et al., 2004). The failure of PFZ restorations often involves crack initiation during the firing the porcelain onto zirconia and its growth in the porcelain, which can increase probability of chipping and delamination of the porcelain layer (Chai et al., 2014). One of the main reasons of high fracture rates observed in PFZ is deleterious tensile residual stresses (Baldassarri et al., 2012; Hermann et al., 2006; Mainjot et al., 2012; Meira et al., 2013; Swain, 2009). In addition, when a crack growing reaches the interface between the veneer and zirconia, it reflects into the porcelain layer as the zirconia core is stiffer and tougher or grows along the weak interface (Coelho et al., 2009; Wang et al., 2013). Therefore, there are two challenges to deal with: (1) proper engineering of the interface; (2) lowering thermal residual stresses in porcelain layer. The developed PSO model is adjusted to minimize thermal residual stresses generated in the porcelain layer during fabrication. Moreover, the optimal FG structure leads to vary material properties from the core to the veneer smoothly. Therefore, the layer that places just below the veneer is not as stiff as the zirconia. Consequently, the crack may penetrate into the next layer underneath the veneer and finally effectively hold off the crack. With defining an objective function to minimize tensile residual stresses in the veneer, optimal designs of functionally-graded PFZ restorations consisting of different numbers of layers are obtained and listed in Table 6. $\sigma_{1}$ represents the resultant stress along the bottom surface of the veneer layer while $\sigma_{2}$ is tensile stress at its top surface. The maximum mismatch stress $\left(\sigma_{m i s}\right)$ takes place along the interface constituted by the core and the second layer. The FGC design with three layers reveals the 
Table 6

Obtained design variables to minimize thermal residual stresses within the porcelain layer.

\begin{tabular}{|c|c|c|c|c|c|c|c|c|c|c|c|c|}
\hline \multirow{2}{*}{$\begin{array}{l}\text { No. of layers } \\
n\end{array}$} & \multicolumn{9}{|c|}{ Design variables } & \multicolumn{3}{|c|}{ Stress (MPa) } \\
\hline & $t_{2}$ & $t_{3}$ & $t_{4}$ & $t_{5}$ & $t_{6}$ & $t_{7}$ & $t_{8}$ & $t_{9}$ & $P$ & $\sigma_{1}$ & $\sigma_{2}$ & $\sigma_{m i s}$ \\
\hline 3 & 1.6 & & & & & & & & 0.68 & -7.98 & 6.47 & 72.67 \\
\hline 4 & 1.39 & 0.21 & & & & & & & 0.54 & -8.15 & 6.68 & 67.40 \\
\hline 5 & 0.73 & 0.78 & 0.09 & & & & & & 0.62 & -8.23 & 7.08 & 56.23 \\
\hline 6 & 0.13 & 0.87 & 0.55 & 0.05 & & & & & 0.75 & -8.33 & 6.93 & 43.18 \\
\hline 7 & 0.16 & 0.57 & 0.63 & 0.15 & 0.09 & & & & 0.72 & -8.31 & 7.19 & 40.15 \\
\hline 8 & 0.06 & 0.31 & 0.46 & 0.57 & 0.13 & 0.07 & & & 0.83 & -8.33 & 7.25 & 30.36 \\
\hline 9 & 0.06 & 0.36 & 0.42 & 0.50 & 0.16 & 0.05 & 0.05 & & 0.71 & -8.46 & 7.02 & 34.42 \\
\hline 10 & 0.05 & 0.29 & 0.55 & 0.39 & 0.15 & 0.05 & 0.07 & 0.05 & 0.64 & -8.38 & 7.08 & 36.34 \\
\hline
\end{tabular}

Table 7

A comparison of the optimal design with six design cases reported in Fabris et al. (2016).

\begin{tabular}{|c|c|c|c|c|c|c|c|}
\hline \multirow[b]{2}{*}{$n$} & \multicolumn{6}{|c|}{ Design variables } & \multirow{2}{*}{$\begin{array}{l}\text { Maximum stress } \\
\sigma_{M}(\mathrm{MPa})\end{array}$} \\
\hline & $t_{2}$ & $t_{3}$ & $t_{4}$ & $t_{5}$ & $t_{6}$ & $p$ & \\
\hline Case 1 & 0.002 & 0.038 & 0.166 & 0.448 & 0.944 & 0.25 & 697.0 \\
\hline Case 2 & 0.064 & 0.192 & 0.320 & 0.448 & 0.576 & 0.5 & 651.4 \\
\hline Case 3 & 0.320 & 0.320 & 0.320 & 0.320 & 0.320 & 1 & 617.1 \\
\hline Case 4 & 0.715 & 0.296 & 0.227 & 0.192 & 0.169 & 2 & 599.4 \\
\hline Case 5 & 1.070 & 0.202 & 0.135 & 0.105 & 0.087 & 4 & 580.4 \\
\hline Case 6 & 1.310 & 0.119 & 0.74 & 0.055 & 0.044 & 8 & 557.8 \\
\hline Optimal design & 0.704 & 0.746 & 0.050 & 0.050 & 0.050 & 8 & 504.7 \\
\hline
\end{tabular}

minimum tensile residual stress and the corresponding compositional exponent is 0.68. However, this optimal design shows the highest mismatch stress, $72.67 \mathrm{MPa}$, which is considered a drawback. If one looks at obtained outcomes, the lowest mismatch stress belongs to the design with eight layers, $30.36 \mathrm{MPa}$, where the porcelain tensile stress shows a value of $7.19 \mathrm{MPa}$ and compositional exponent is 0.83 . Moreover, the lowest mismatch stress takes place along the interface attached to the veneer for all those optimal designs listed in Table 6 . The developed optimization model, therefore, allows for an optimal design in order for lowering thermal residual stresses in more brittle layers of PFZ restorations. It is worth noting that desired thicknesses of the zirconia and porcelain layers can be amended based upon design criteria before optimizing design variables of the functionally graded structure.

\subsection{Minimizing bending stresses due to the piston-on-ring test}

In this section, the geometry and loading conditions are considered identical with the reference by Fabris et al. (2016), to validate the developed model and to prove the capability of the optimization to minimize stresses by controlling design variables. The bottom and top layers of this case study have $0.2 \mathrm{~mm}$ thickness and the overall size of the intermediate layers is $1.6 \mathrm{~mm}$. For each compositional distribution exponent listed in the Table 7 , corresponding thicknesses and mechanical properties of each layer is estimated by Eq. (2). The optimal

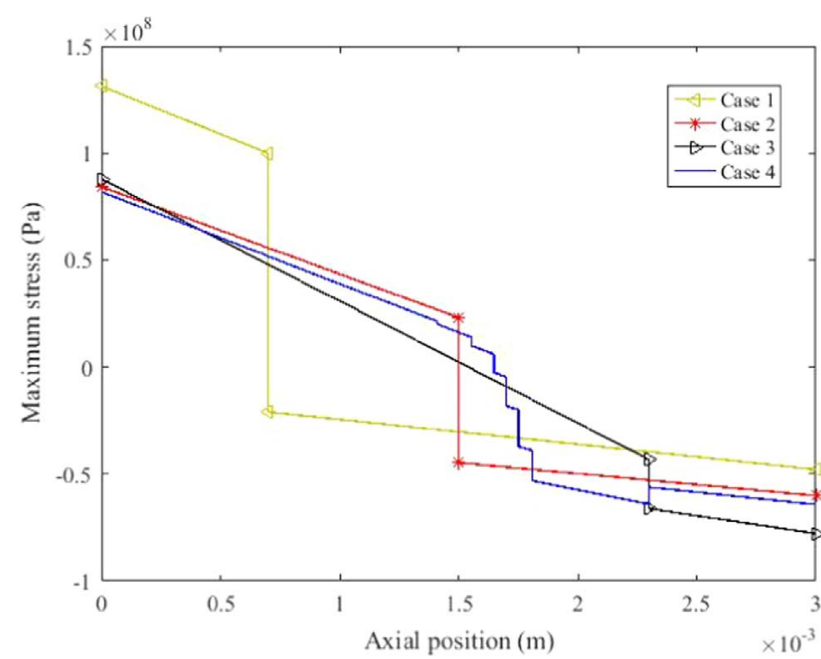

Fig. 5. Stress distribution due to thermal residual stresses and the piston-on-ring test along the central axis for four cases: (1) sharp transition with $0.7 \mathrm{~mm} \mathrm{Zr}$ layer; (2) sharp transition with $1.5 \mathrm{~mm} \mathrm{Zr}$ layer; (3) optimal design with three layers; (4) optimal design with 9 layers. Corresponding mismatch stresses are: (1) $121 \mathrm{MPa}$; (2) $67.7 \mathrm{MPa}$; (3) 22.87 MPa; (4) $17.02 \mathrm{MPa}$.

Table 9

Corresponding Young's Modulus of each layer presented in Table 6 for the disc subjected to both thermal stresses and the piston-on-ring test.

\begin{tabular}{llllllllll}
\hline \multirow{2}{*}{$\begin{array}{l}\text { No. of } \\
\text { layers } \\
n\end{array}$} & \multicolumn{2}{l}{ Young's modulus (GPa) } \\
\cline { 2 - 10 } & $t_{2}$ & $t_{3}$ & $t_{4}$ & $t_{5}$ & $t_{6}$ & $t_{7}$ & $t_{8}$ & $t_{9}$ \\
\hline 3 & 209.86 & & & & & & & \\
4 & 208.53 & 183.98 & & & & & & \\
5 & 208.84 & 197.28 & 158.26 & & & & & \\
6 & 209.30 & 203.13 & 183.92 & 142.81 & & & & \\
7 & 209.65 & 206.47 & 196.27 & 174.01 & 133.99 & & & \\
8 & 209.79 & 207.84 & 201.67 & 188.28 & 164.34 & 126.21 & & \\
9 & 209.89 & 208.83 & 205.25 & 197.19 & 182.34 & 158.11 & 121.68 & \\
10 & 209.98 & 209.66 & 208.27 & 204.54 & 196.66 & 182.35 & 158.77 & 122.60 \\
\hline
\end{tabular}

Table 8

Optimal outcomes of the design variables for the disc subjected to thermal stresses and biaxial flexure test.

\begin{tabular}{|c|c|c|c|c|c|c|c|c|c|c|}
\hline \multirow{2}{*}{$\begin{array}{l}\text { No. of layers } \\
n\end{array}$} & \multicolumn{9}{|c|}{ Design variables } & \multirow{2}{*}{$\begin{array}{l}\text { Maximum stress } \\
\sigma_{M}(\mathrm{MPa})\end{array}$} \\
\hline & $t_{2}$ & $t_{3}$ & $t_{4}$ & $t_{5}$ & $t_{6}$ & $t_{7}$ & $t_{8}$ & $t_{9}$ & $p$ & \\
\hline 3 & 1.6 & & & & & & & & 10 & 87.89 \\
\hline 4 & 1.052 & 0.548 & & & & & & & 4.15 & 86.04 \\
\hline 5 & 1.004 & 0.050 & 0.561 & & & & & & 3.46 & 83.88 \\
\hline 6 & 0.964 & 0.050 & 0.050 & 0.536 & & & & & 3.29 & 82.79 \\
\hline 7 & 0.787 & 0.186 & 0.055 & 0.064 & 0.508 & & & & 3.35 & 82.35 \\
\hline 8 & 0.776 & 0.154 & 0.052 & 0.062 & 0.054 & 0.502 & & & 3.33 & 82.05 \\
\hline 9 & 0.708 & 0.146 & 0.094 & 0.051 & 0.053 & 0.056 & 0.493 & & 3.45 & 81.93 \\
\hline 10 & 0.384 & 0.417 & 0.050 & 0.099 & 0.050 & 0.050 & 0.061 & 0.489 & 4.00 & 81.95 \\
\hline
\end{tabular}




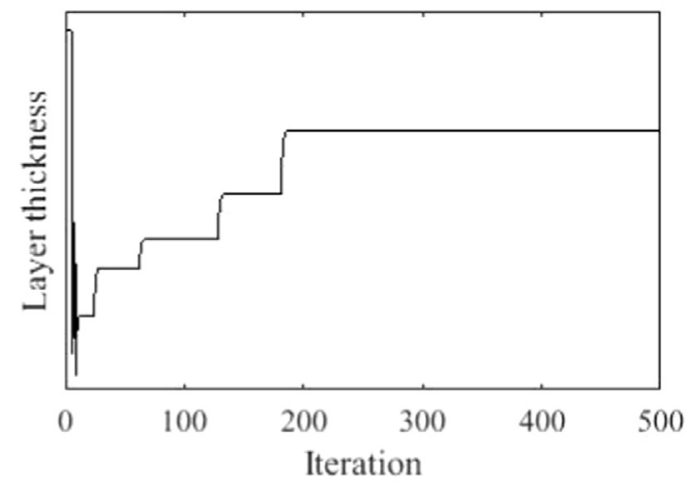

Fig. 6. Convergence rate of the optimization procedure.

design of this specimen is also examined by the developed optimizer and consequent designs are listed in the last raw of the table. The outcomes associated with the optimal design can be compared to six design cases reported in Fabris et al. (2016). As it can be seen, the maximum tensile stress decreases greater than $38 \%$ compared to the case 1 and it is less than $10 \%$ compared to the case 6 which is the best design suggested by Fabris et al. (2016). The optimization algorithm suggests that the layers near to the bottom should have greater thicknesses and more composition exponent, that is, the corresponding material properties are more close to the zirconia. The maximum stresses obtained by the present model for six cases listed in Table 5 align well with those reported by Fabris et al.

\subsection{Minimization of both TRS and biaxial bending stress}

The disc is cooled from $550{ }^{\circ} \mathrm{C}$ to $20^{\circ} \mathrm{C}$ and the thermal residual stresses are computed and used as initial conditions in the piston-onring test to acquire the tensile stresses within the graded dental prostheses. The maximum tensile stress for a sharp transition from the zirconia to porcelain layer is obtained being $131.27 \mathrm{MPa}$, where the bottom layer has a thickness of $0.7 \mathrm{~mm}$, while the thickness of the porcelain layer is $2.3 \mathrm{~mm}$. Moreover, optimal designs of multi-layered disc with different layer numbers are listed in Table 8 . As it can be seen, up to nine layers, the greater the number of interlayers of which the disc is consisted is, the less maximum thermal residual stresses obtained. The maximum stress reported for the case with a sharp transition is 1.60 times greater than the design with 9 inter-layers. The maximum decrease occurs as one layer is added as interlayer, but the mechanical property of this added layer is very close to the zirconia according to $p=10$. Table 8 also lists Young's modulus of intermediate layers associated with corresponding optimized designs listed in Table 8.

Fig. 5 depicts stress distribution along the central axis of the graded disc due to both thermal residual stresses and the piston-on-ring test. Two different sharp transitions are studied one of which has $0.7 \mathrm{~mm}$ thickness of zirconia layer and another $1.5 \mathrm{~mm}$. moreover, taking a look at Table 9, the optimal design with three layers is very similar to have a sharp transition with zirconia thickness of $2.3 \mathrm{~mm}$. Increasing the thickness of zirconia layer causes resulting stresses and mismatch stresses to decrease considerably. However, the point is how thin the porcelain layer can be to prevent failure and veneer chipping. Generally, the least maximum stress belongs to the optimized design with nine layers. Moreover, the maximum mismatch stress occurs in this case is $17 \mathrm{MPa}$, while it is $23 \mathrm{MPa}$ for the case 3, as shown in Fig. 5. The information obtained and discussed can be very helpful to be taken into account for designing the best prosthesis in terms of both manufacturing limitations and application-based standards.
The convergence rate of the optimization procedure is also studied and shown in Fig. 6. The thickness of an intermediate layer convergences to a constant amount, while the convergence study for all cases studied illustrates the convergence occurs after 250 iteration, which shows the PSO is a fast procedure. The maximum stresses and stress distribution profiles corresponding the optimal designs are compared to the finite element model constructed in the present study and a very good agreement has been observed with a maximum discrepancy of $7 \%$.

\section{Conclusion}

A particle swarm optimization algorithm was developed to identify optimal designs of zirconia-based dental restorations to minimize resulting stresses due to cooling down from the processing temperature and the piston-on-ring test. An analytical model based on laminate theory was used to estimate the TRS in graded dental prosthesis and the Hsueh's model was employed to predict bending stresses in graded zirconia systems. The developed analytical models were embedded in an optimization procedure based on the particle swarm algorithm to reduce stresses in graded dental restorations by designing the thicknesses and compositional distribution of the prosthesis. The model was validated comparing acquired results with those available in literature and obtained from a finite element analysis. Moreover, the convergence study showed the PSO is a very fast optimization procedure.

Results obtained from the developed optimization model can be very helpful for decision-making process to design the best graded prosthesis fulfilling criteria associated with manufacturing and bio-application. Moreover, the model can be extended to take into account more realistic geometries of implant, surrounding bones, occlusal loads and etc. by employing CAD models and finite element method coupled with a PSO algorithm. The optimized designs for different scenarios were obtained where both minimum stresses and mismatch stresses took place. Optimization outcomes also illustrated that design variables significantly influenced resulting stress fields and magnitudes.

\section{References}

Askari, E., Flores, P., Dabirrahmani, D., Appleyard, R., 2015. A computational analysis of squeaking hip prostheses. ASME J. Comput. Nonlinear Dyn. 10 (2).

Askari, E., Flores, P., Dabirrahmani, D., Appleyard, R., 2016. A review of squeaking in ceramic total hip arthroplasty. Tribol. Int. 93, 239-256.

Baldassarri, M., Zhang, Y., Thompson, V.P., Rekow, E.D., Stappert, C.F.J., 2011. Reliability and failure modes of implant-supported zirconium-oxide fixed dental prostheses related to veneering techniques. J. Dent. 39, 489-498.

Baldassarri, M., Stappert, C.F.J., Wolff, M.S., Thompson, V.P., Zhang, Y., 2012. Residual stresses in porcelain-veneered zirconia prostheses. Dent. Mater. 28, 873-879.

Becker, T.L., Cannon, R.M., Ritchie, R.O., 2000. An approximate method for residual stress calculation in functionally graded materials. Mech. Mater. 32, 85-97.

Benetti, P., Della Bona, A., Kelly, J.R., 2010. Evaluation of thermal compatibility between core and veneer dental ceramics using shear bond strength test and contact angle measurement. Dent. Mater. 26, 743-750.

Besisa, D.H.A., Ewais, E.M.M., 2016. Advances in functionally graded ceramics - processing, sintering properties and applications. In: Farzad, Ebrahimi (Ed.), Advanced in Functionally Graded Materials and Structures. INTECH.

Birman, V., Byrd, L.W., 2007. Modeling and analysis of functionally graded. Mater. Struct. 60, 195-215.

Bouchafa, A., Benzair, A., Tounsi, A., Draiche, K., Mechab, I., Bedia, E.A.A., 2010. Analytical modelling of thermal residual stresses in exponential functionally graded material system. Mater. Des. 31, 560-563.

Cannillo, V., Montorsi, M., Siligardi, C., Sola, A., de Portu, G., Micele, L., Pezzotti, G., 2006. Microscale computational simulation and experimental measurement of thermal residual stresses in glass-alumina functionally graded materials. J. Eur. Ceram. Soc. 26, 1411-1419.

Chai, H., Lee, J.J.W., Mieleszko, A.J., Chu, S.J., Zhang, Y., 2014. On the interfacial fracture of and graded zirconia dental. Acta Biomater. 10 (8), 3756-3761.

Chang, N., Wang, W., Yang, W., Wang, J., 2010. Ply stacking sequence optimization of composite laminate by permutation discrete particle swarm optimization. Struct. Multidiscip. Optim. 41 (2), 179-187.

Chen, B., Tong, L., 2005. Thermomechanically coupled sensitivity analysis and design 
optimization of functionally graded materials. Comput. Methods Appl. Mech. Eng. 194, 1891-1911.

Choi, J.E., Waddell, J.N., Swain, M.V., 2011. Pressed ceramics onto zirconia. Part 2: indentation fracture and influence of cooling rate on residual stresses. Dent. Mater. 27, 1111-1118.

Coelho, P.G., Silva, N.R., Bonfante, E.A., Guess, P.C., Rekow, E.D., Thompson, V.P., 2009. Fatigue testing of two porcelain-zirconia all-ceramic crown systems. Dent. Mater. 25, $1122-1127$.

DeHoff, P.H., Anusavice, K.J., 2009. Viscoelastic finite element stress analysis of the thermal compatibility of dental bilayer ceramic systems. Int. J. Prosthodont. 22, 56-61.

Denry, I., Kelly, J.R., 2008. State of the art of zirconia for dental applications. Dent. Mater. 24, 299-307.

Eberhart, R.C., Shi, Y., 2001. Particle swarm optimization: developments, applications and resources. IEEE Congr. Evol. Comput. 81-86.

Fabris, D., Souza, J.C.M., Silva, F.S., Fredel, M., Mesquita-Guimarães, J., Zhang, Y., Henriques, B., 2016. The bending stress distribution in bilayered and graded zirconiabased dental ceramics. Ceram. Int. 42 (9), 11025-11031.

Fereidoon, A., Sadri, F., Hemmatian, H., 2012. Functionally graded materials optimization using particle swarm-based algorithms. J. Therm. Stress. 35, 377-392.

Fischer, J., Stawarczyk, B., Hämmerle, C.H.F., 2008. Flexural strength of veneering ceramics for zirconia. J. Dent. 36, 316-321.

Fourie, P.C., Groenwold, A.A., 2002. The particle swarm optimization algorithm in size and shape optimization. Struct. Multidiscip. Optim. 23 (4), 259-267.

He, S., Wu, Q.H., Wen, J.Y., Saunders, J.R., Paton, R.C., 2004a. A particle swarm optimizer with passive congregation. Biosystem 78, 135-147.

He, S., Prempain, E., Wu, Q.H., 2004b. An improved particle swarm optimizer for mechanical design optimization problems. Eng. Optim. 36 (5), 585-605.

Henriques, B., Gasik, M., Soares, D., Silva, F.S., 2012a. Experimental evaluation of the bond strength between a CoCrMo dental alloy and porcelain through a composite metal ceramic graded transition interlayer. J. Mech. Behav. Biomed. Mater. 13, 206-214.

Henriques, B., Gonçalves, S., Soares, D., Silva, F.S., 2012b. Shear bond strength comparison between conventional porcelain fused to metal and new functionally graded dental restorations after thermal-mechanical cycling. J. Mech. Behav. Biomed. Mater. 13, 194-205.

Hermann, I., Bhowmick, S., Zhang, Y., Lawn, B.R., 2006. Competing fracture modes in brittle materials subject to concentrated cyclic loading in liquid environments: trilayer structures. J. Mater. Res. 21, 512-521.

Hsueh, C.H., Luttrell, C.R., Becher, P.F., 2006a. Analyses of multilayered dental ceramics subjected to biaxial flexure tests. Dent. Mater. 22, 460-469.

Hsueh, C.H., Luttrell, C.R., Becher, P.F., 2006b. Modelling of bonded multilayered disks subjected to biaxial flexure tests. Int. J. Solids Struct. 43, 6014-6025.

Hsueha, C.H., Thompson, G.A., Jadaan, O.M., Wereszczak, A.A., Becher, P.F., 2008. Analyses of layer-thickness effects in bilayered dental ceramics subjected to thermal stresses and ring-on-ring tests. Dent. Mater. 24, 9-17.

Huang, C.W., Hsueh, C.H., 2011. Piston-on-three-ball versus piston-on-ring in evaluating the biaxial strength of dental ceramics. Dent. Mater. 27, 117-123.

Isgrò, G., Wang, H., Kleverlaan, C.J., Feilzer, A.J., 2005. The effects of thermal mismatch and fabrication procedures on the deflection of layered all-ceramic discs. Dent. Mater. 21, 649-655.

Jha, D.K., Kant, T., Singh, R.K., 2013. A critical review of recent research on functionally graded plates. Compos. Struct. 96, 833-849.

Jun, Y., Hajirasouliha, I., Becque, J., Eslami, A., 2016. Optimum design of cold-formed steel beams using particle swarm optimisation method. J. Const. Steel Res. 122, 80-93.

Kathiravan, R., Ganguli, R., 2007. Strength design of composite beam using gradient and particle swarm optimization. Compos. Struct. 81, 471-479.

Kennedy, J., Eberhart, R., 1995. Particle swarm optimization. In: Proceedings of the IEEE International Conference on Neural Networks. IEEE Press. 4, pp. 1942-1948.

Kesler, O., Matejicek, J., Sampath, S., Suresh, S., Gnaeupel-Herold, T., Brand, P.C., Prask, H.J., 1998. Measurement of residual stress in plasma-sprayed metallic, ceramic and composite coatings. Mater. Sci. Eng. A257, 215-224.

Koohbor, B., Mallon, S., Kidane, A., Anand, A., Parameswaran, V., 2015. Through thickness elastic profile determination of functionally graded materials. Exp. Mech. $55,1427-1440$.

Li, L.J., Huang, Z.B., Liu, F., Wu, Q.H., 2007. A heuristic particle swarm optimizer for optimization of pin connected structures. Comput. Struct. 85, 340-349.

Liu, Z., Lu, J., Zhu, P., 2016. Light weight design of automotive composite bumper system using modified particle swarm optimizer. Compos. Struct. 140, 630-643.

Loja, M.A.R., 2014. On the use of particle swarm optimization to maximize bending stiffness of functionally graded structures. J. Symb. Comput. 61-62, 12-30.

Mainjot, A.K., Schajer, G.S., Vanheusden, A.J., Sadoun, M.J., 2012. Influence of zirconia framework thickness on residual stress profile in veneering ceramic: measurement by hole-drilling. Dent. Mater. 28, 378-384.

Mashhadban, H., Soleimani-Kutanaei, S., Sayarinejad, M.A., 2016. Prediction and modeling of mechanical properties in fiber reinforced self-compacting concrete using particle swarm optimization algorithm and artificial neural network. Const. Build. Mater. 119, 277-287.

Mavrovouniotis, M., Li, C., Yang, S., 2017. A survey of swarm intelligence for dynamic optimization: algorithms and applications. Swarm Evol. Comput. 33, 1-17.

Meira, J.B., Reis, B.R., Tanaka, C.B., Ballester, R.Y., Cesar, P.F., Versluis, A., et al., 2013 Residual stresses in Y-TZP crowns due to changes in the thermal contraction coefficient of veneers. Dent. Mater. 29, 594-601.

Mohammadiha, O., Beheshti, H., 2014. Optimization of functionally graded foam-filled conical tubes under axial impact loading. J. Mech. Sci. Technol. 28 (5), 1741-1752.

Mortensen, A., Suresh, S., 1995. Functionally graded metals and metal-ceramic composites: Part 1 processing. Int. Mater. Rev. 40 (6), 239-265.

Moshkelgosha, E., Askari, E., Jeong, K.H., Shafiee, A.A., 2017. Fluid-structure coupling of concentric double FGM shells with different lengths. Struct. Eng. Mech. 61 (2), $231-244$.

Naebe, M., Shirvanimoghaddam, K., 2016. Functionally graded materials: a review of fabrication and properties. Appl. Mater. Today 5, 223-245.

Paul, I.I., Hu, X., Bazen, J.J., Yi, W., 2016. Design optimization of a radial functionally graded dental implant. J. Biomed. Mater. Res. Part B: Appl. Biomater. 104 (1), 58-66.

Ravichandran, K.S., 1995. Thermal residual stresses in a functionally graded material system. Mater. Sci. Eng. A201, 269-276.

Sailer, I., Gottnerb, J., Kanelb, S., Hammerle, C.H., 2009. Randomized controlled clinical trial of zirconia-ceramic and metal-ceramic posterior fixed dental prostheses: a 3-year follow-up. Int. J. Prosthodont. 22, 553-560.

Sax, C., Hammerle, C.H., Sailer, I., 2011. 10-Year clinical outcomes of fixed dental prostheses with zirconia frameworks. Int. J. Comput. Dent. 14, 183-202.

Shafiee, A.A., Daneshmand, F., Askari, E., Mahzon, M., 2014. Dynamic behavior of a functionally graded plate resting on Winkler elastic foundation and in contact with fluid. Struct. Eng. Mech. 50 (1), 53-71.

Shaw, L.L., 1998. Thermal residual stresses in plates and coatings composed of multilayered and functionally graded materials. Compos. Part B: Eng. 29 (3), 199-210.

Shi, Y., Eberhart, R.C., 1997. A modified particle swarm optimizer. In: Proceedings of the IEEE International Conference on Evolutionary Computation. pp. 303-308.

Stump, F.V., Silva, E.C.N., Paulino, G.H., 2007. Optimization of material distribution in functionally graded structures with stress constraints. Commun. Numer. Methods Eng. 23, 535-551.

Suresh, S., Mortensen, A., 1997. Functionally graded metals and metal-ceramic composites: Part 2 thermomechanical behavior. Int. Mater. Rev. 42 (3), 85-116.

Swain, M.V., 2009. Unstable cracking (chipping) of veneering porcelain on all-ceramic dental crowns and fixed partial dentures. Acta Biomater. 5, 1668-1677.

Tan, K., Pjetursson, B.E., Lang, N.P., Chan, E.S., 2004. A systematic review of the survival and complication rates of fixed partial dentures (FPDs) after an observation period of at least 5 years. Clin. Oral Implant. Res. 15, 654-666.

Tholey, M.J., Swain, M.V., Thiel, N., 2011. Thermal gradients and residual stresses in veneered Y-TZP frameworks. Dent. Mater. 27, 1102-1110.

Thompson, G.A., 2004. Determining the slow crack growth parameter and weibull twoparameter estimates of bilaminate disks by constant displacement-rate flexural testing. Dent. Mater. 20, 51-62.

Tsukada, G., Sueyoshi, H., Kamibayashi, H., Tokuda, M., Torii, M., 2014. Bending strength of zirconia/porcelain functionally graded materials prepared using spark plasma sintering. J. Dent. 42, 1569-1576.

Villefort, R.F., et al., 2017. Effects of two grading techniques of zirconiamaterial on the fatigue limit of full-contour 3-unitfixed dental prostheses. Dent. Mater. 33, 155-164.

Wang, R., Lu, C., Arola, D., Zhang, D., 2013. Plastic damage induced fracture behaviors of dental ceramic layer structures subjected to monotonic load. J. Prosthodont. 22, 456-564.

Xu, Y., Zhang, W., Chamoret, D., Domaszewski, M., 2012. Minimizing thermal residual stresses in C/SIC functionally graded material coating of C/C composites by using particle swarm optimization algorithm. Comput. Mater. Sci. 61, 99-105.

Zarone, F., Russo, S., Sorrentino, R., 2011. From porcelain-fused-to-metal to zirconia: clinical and experimental considerations. Dent. Mater. 27, 83-96.

Zhang, Y., Kim, J.W., 2009. Graded structures for damage resistant and aesthetic all ceramic restorations. Dent. Mater. 25, 781-790.

Zhang, Y., Kim, J.W., 2010. Graded zirconia glass for resistance to veneer fracture. J. Dent. Res. 89, 1057-1062.

Zhang, Y., Chai, H., Lawn, B.R., 2010. Graded structures for all-ceramic restorations. J. Dent. Res. 89 (4), 417-421.

Zhang, Y., Sun, M.J., Zhang, D., 2012. Designing functionally graded materials with superior load-bearing properties. Acta Biomater. 8, 1101-1108.

Zhang, Z., Zhou, S., Li, Q., Li, W., Swain, M.V., 2012. Sensitivity analysis of bi-layered ceramic dental restorations. Dent. Mater. 28 (2), 6-14. 